\title{
The application of Quadrifid Graphs Model in content system optimization of the vocational course based on working process -taking the course of Techniques of Car Sales for example
}

\author{
Yan $\mathrm{Du}^{1}$ and Ning Sun ${ }^{1}$ \\ Zhejiang Agricultural Business College, Zhejiang, 312008, China \\ ${ }^{1}$ suning_aini@163.com
}

Keywords: Course reform, quadratic graphs model, working process, techniques of car sales.

\begin{abstract}
In this paper, taking < Techniques of Car Sales> as example, the working process based vocational course system is optimized and established by employing Quadrifid Graphs Model analysis method. The new course system can achieve the job vocational capacity of automobile sales consultant accurately and definitize the reform trend of <Techniques of Car Sales $>$ in the future. In the proposed method, the reliability and validity of the survey data are checked to verify the reasonability and effectiveness of the questionnaire next; the importance and satisfaction degree of evaluation index are calculated, the Quadrifid Graphs Model of <Techniques of Car Sales> is established, and the teaching content system is optimized recording to analysis results.
\end{abstract}

\section{Introduction}

With the rapid development of economy, the demand for technology applied talents is becoming increasingly urgent and the vocational education presents a good development trend. According to the spirit of < Decision on Accelerating the Development of Modern Vocational Education > issued by State Council, the theme of vocational education at present stage is the reform and development, domestic vocational colleges have actively explored the reform and innovation mode of vocational education [1,2]. Corresponding to related field of automobile after market service, how to make the teach more close to the enterprise practice and cultivate high-quality technical type talent with high quality is the urgent task that automotive after-market service professional development faces.

Some experts and scholars applied the work process oriented vocational education core ideas to deepen the curriculum reform which is based on the German vocational education theory, and some research results were formed. For example, the literature $[3,4,5,6]$ explained the profound connotation of working process oriented curriculum mode. Based on [3], the literatures [7,8,9,10] pointed out that, during the curriculum system reconstruction process which on the basis of working process, the professional skills and knowledge requirements of industry enterprise post (Group) related to the course should be analyzed first, then ability and knowledge goal of course teaching should be explicated, and then ability goal achievement is taken as the core, meanwhile, the typical training programs should be determined.

At present, the construction of <Techniques of Car Sales> course content system based on working process takes the teaching goal that knowledge, ability and quality needed by actual work. Then, teaching module is designed, teaching outline is prepared. So whether the knowledge, ability and quality requirements of actual work a can be obtained accurately is the foundation of curriculum design in the future.

\section{Course Evaluation Method Based on the Quadratic Graphs Model}

Quantization of Index System. During the questionnaire design, five Likert scale method is used to quantify the evaluation index system. And satisfaction rating of the course of graduate is divided into five kinds of degree: very unsatisfied, unsatisfied, generally satisfied, satisfied and very satisfied. The corresponding assignment of this five degrees is $1,2,3,4$ and 5 . The importance of 
evaluation indicators will be divided into the five kinds of degree: very unimportant, unimportant, generally important, important and very important.

Test of Reliability and Validity. In the questionnaire design process, the reasonable and effectiveness of the questionnaire determine the feasibility and availability of evaluation results. The study test the reliability of the questionnaire by inherent reliability analysis first. Cronbach's alpha is used to analyze the reliability. Cronbach $\alpha$ coefficient is as follows:

$$
\alpha=\frac{k \bar{r}}{1+(k-1) \bar{r}}
$$

Where, $\mathrm{K}$ is the amount of evaluation index, $r$ is the mean of $\mathrm{k}$ evaluation index correlation coefficients. Usually, $\alpha$ is more than 0.8 , it can be considered internal reliability of the scale is relatively high; $\alpha$ is less than 0.8 , it can be considered internal reliability of the scale has some problems.

Then, KMO test and Bartlett ball test is conducted to the data. When the KMO test coefficient is more than 0.8, (the $\mathrm{x} 2$ statistics significant probability of Bartlett ball test) when $\mathrm{P}$ is less than0.01, the questionnaire has construct validity, and factor analysis can be performed.

Calculation of Course Evaluation Data. The calculation method of evaluation data is as follows:

(1) Calculating graduate satisfaction for each evaluation indicators in evaluation index system.

$S_{i}=\sum_{j=1}^{n} x_{j} y_{i j}$

Where, $S_{i}$ is the satisfaction of the $\mathrm{i}$-th index; $x_{j}$ is the score when satisfaction index is $\mathrm{j}$ level; $y_{x j}$ is the i-th satisfaction's proportion of the total number of persons when it is j level.

(2) Calculating the importance of each evaluation index to auto sales consultant positions;

$$
I_{i}=\sum_{i=1}^{n} t_{i} z_{i j}
$$

Where, $I_{i}$ is the importance of the $\mathrm{i}$-th index; $t_{i}$ is the score when importance index is $\mathrm{j}$ level; $z_{i j}$ is the $\mathrm{i}$-th importance's proportion of the total number of persons when it is $\mathrm{j}$ level.

\section{Example analysis}

The questionnaire of $<$ Techniques of Car Sales $>$ evaluation adopts the form of personal interview. Sixty questionnaires are issued on the whole, valid questionnaires among them are 58 and questionnaire effective rate is $96.6 \%$.

Reliability and Validity Analysis. The data is got by questionnaires, reliability and validity analysis are made by making use of SPSS14.0 statistical software and the results are as follows.

Table 1 Importance of reliability statistics output table

\begin{tabular}{ccc}
\hline Cronbach's Alpha & Cronbachs Alpha based on standardized items & Numbers \\
\hline .847 & .855 & 20 \\
\hline \multicolumn{2}{c}{ Table 2 Reliability statistics satisfaction of the output table } \\
\hline Cronbach's Alpha & Cronbachs Alpha based on standardized items & Numbers \\
\hline .814 & .813 & 20 \\
\hline
\end{tabular}

The results of reliability statistics represented by Table 1 and Table 2 shows that: the questionnaire of this survey design is effective and credible on the whole, afterwards, the results of KMO and Bartlett test for data are shown in Table 3. 
Table 3 KMO and Bartlett test

\begin{tabular}{c|c|c}
\hline \multicolumn{2}{c|}{ Sampling sufficient degree of Kaiser-Meyer-Olkin measure } & .874 \\
\hline The test of sphericity of Bartlett & Approximate chi-square & 2861.237 \\
& $\mathrm{df}$ & 213 \\
Sig. & .000 \\
\hline
\end{tabular}

As can be seen from Table 3, KMO value is 0.874 , which is more than 0.8 and statistic value $\mathrm{P}$ is 0.000 , which is less than 0.01 ,it demonstrates that, questionnaire has construct validity, sample concentration appropriately and the data is suitable for factor analysis.

Quadrifid Graphs Model. According to the above formula, the degree of satisfaction and importance of the graduates who majored in the automobile sales consultant about the $<$ Techniques of Car Sales> is calculated, then the results are used to draw the Quadrifid graphs, it is represented as Figure 1.

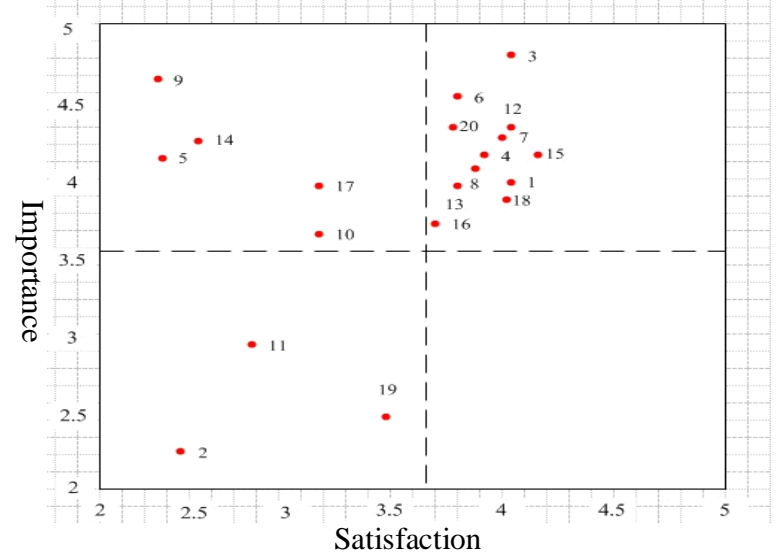

Fig.1

It can be seen that: the methods and techniques used to explore the needs of customers, FABE sales skills for customer needs, comparative analysis of competitive brands, methods and skills of price negotiations, maintenance, daily maintenance, use of attention and other factors are located in District B, that is, these need to be paid attention to during the construction of the curriculum system. So the content of <Techniques of Car Sales> should be optimized:

(1) The needs of different levels of automotive customers group should be analyzed and trained;

(2) The products should be introduced according to customer needs and benefits.

(3) Different price negotiation methods should be adopted for different customers.

(4) Knowledge of daily maintenance and use of attention should be strengthened to be grasped.

\section{Summary}

Quadrifid graphs model is used in this paper, which combines with the empirical analysis of $<$ Techniques of Car Sales>, research on the evaluation of satisfaction index in the process of car sales by car sales consultant is conducted, which is an effective method to further clarify the rationality of the design of the course content and the teaching effect, with the characteristics of the pertinence, applicability and intuition. It has certain practical application significance to the future teaching. But for the application of the Quadrifid graphs model, it needs to improve the index system, so as to better guide the course teaching and improve the teaching effect.

\section{Acknowledgments}

The authors would like to acknowledge the support of the Reform of Higher Education Classroom Project of Zhejiang Province (kg2013984), Major Scientific and Technological Platform Project of Shaoxing(2013C1007), and Excellent Course Project of Shaoxing. The corresponding author is Ning sun, and her email is sunning_aini@163.com. 


\section{References}

[1] H.B. Liu, Development and reform of higher vocational education curriculum model, J. Education and occupation, 15, (2011) 133-134.

[2] C. Hao. Exploration and Research on the curriculum model of Higher Vocational Education, D. Nanjing University of Science and Technology. 2007.

[3] H. Nie. Vocational education thought and its value in the work process of Germany, D. East China Normal University. 2009.

[4] G. Deng, W. Fu. The basic connotation of the process oriented curriculum in Higher Vocational Education, J. Higher education in China. 41(2010) 73-75.

[5] M. Lou. Exploration on the development of higher vocational education curriculum standards, J. Vocational and technical education. 17 (2008) 19-20.

[6] D Jiang. "Learning field" - the course model of work process oriented, J. Vocational Education Forum, 8 (2004) 61-64.

[7] C. Y Qin. Reconstruction of curriculum content system of Higher Vocational Education Based on working process, J. Vocational Education Forum. 5 (2010) 50-52.

[8] Y.H. Tang, C.Q. He. Reconstruction of curriculum system based on working process, J. Vocational and technical education. 29 (2008) 19-20.

[9] J.L. Hu. Customer relationship management, M. Beijing: Beijing Institute of Technology press, 2012.

[10] J.B. Jiang, J. Gao. Based on the four point map model of the hot spring tourist satisfaction evaluation and Its Application Research -- take Longwan natural hot spring resort as an example, J. Tropical geography, 31(2011) 100-106 . 